\title{
Invertebrate settlement and diversity on a glass sponge reef
}

\author{
Stephanie K. Archer ${ }^{1,2, *}$, Glen Dennison ${ }^{3}$, Lora Tryon $^{4}$, Sheila Byers $^{5}$, and Anya \\ DUNHAM ${ }^{1}$
}

\begin{abstract}
${ }^{1}$ Fisheries and Oceans Canada, Pacific Biological Station, 3190 Hammond Bay, Nanaimo, British Columbia V9T 6N7 Canada ${ }^{2}$ Current address: Louisiana Universities Marine Consortium, 8124 Highway 56, Chauvin, Louisiana 70344 USA

${ }^{3}$ Triumf, 4004 Wesbrook Mall, Vancouver, British Columbia V6T 2A3 Canada

${ }^{4}$ Lake Trail Environmental Consulting, P.O. Box 1746, Garibaldi Highlands, British Columbia V0N 1T0 Canada

${ }^{5}$ Beaty Biodiversity Museum, University of British Columbia, 2212 Main Mall, Vancouver, British Columbia V6T 1Z4

Canada

*Corresponding author: sarcher@lumcon.edu
\end{abstract}

Archer, S.K., G. Dennison, L. Tryon, S. Byers, and A. Dunham. 2020. Invertebrate settlement and diversity on a glass sponge reef. Canadian Field-Naturalist 134(1): 1-15. https://doi.org/10.22621/cfn.v134i1.2297

\begin{abstract}
Glass sponge reefs are an ecosystem unique to the continental shelf of the northeast Pacific Ocean. Due to their vulnerability and limited distribution, several sponge reef protection initiatives exist within Canadian waters with the common goal of conserving biodiversity. To date, the biodiversity associated with sponge reefs has largely been assessed using remote video methods that allow us to describe large fauna associated with the reefs. However, small organisms are typically missed, resulting in an underestimate of reef-associated biodiversity. In this study we aimed to further describe invertebrate biodiversity associated with sponge reefs. Sponge reefs recently discovered in Howe Sound, British Columbia are within safe recreational SCUBA diving limits allowing us to examine macrofaunal settlement timing and community structure using diver-deployed settlement plates. We examined the effect of settlement plate material and elevation above the benthos within the reef on invertebrate community structure. A total of 70 taxa settled on the plates representing 10 phyla, including two phyla not previously described on sponge reefs: Nemertea (ribbon worms) and Platyhelminthes (flatworms). There were no significant differences in taxa richness, diversity, or community structure associated with settlement plate material or height above the benthos. Ours is the first report of invertebrate settlement on a sponge reef in the Salish Sea and the first description of larval settlement timing for nine invertebrate species in the northeast Pacific.
\end{abstract}

Key words: Glass sponge reefs; invertebrates; Porifera; community structure; juvenile settlement

\section{Introduction}

Glass sponge reefs, an ecosystem unique to the continental shelf of the northeast Pacific Ocean, are found from the Salish Sea in the south to Portland Canal, on the Canada-Alaska border in the north (Conway et al. 1991; Stone et al. 2014; Dunham et al. 2018). The sponge reefs are large biogenic structures that play an important role in carbon, nitrogen, and silica cycling and support more diverse and abundant faunal communities than the surrounding sea floor (Chu and Leys 2010; Chu et al. 2011; Kahn et al. 2015, 2018; Maldonado et al. 2016; Dunham et al. 2018). The reefs are formed by three species of glass sponges: Cloud Sponge (Aphrocallistes vastus), Farrea occa (no common name and absent on reefs in the Salish Sea), and Goblet Sponge (Heterochone ca$l y x)$. These sponges occur throughout the world but have only been reported to form reefs in the northeast Pacific. They can form reefs because they pos- sess skeletons of fused silica spicules which maintain their three-dimensional structure after the sponges' death. The erect dead sponge skeletons serve as settlement substrate for juvenile sponges and are infilled with baffled sediment, a process that results in reef formation after multiple generations of sponges. While the sponge skeletons are rigid, they are fragile. Consequently, the sponges and reefs are vulnerable to damage from human activities that contact the bottom, such as trawl and trap fishing, and cable laying (Dunham et al. 2015; Kahn et al. 2016). Because of their vulnerability to human impacts and their limited global distribution the sponge reefs are a high conservation priority in Canada. As a result, one marine protected area (MPA) and 17 bottom contact fishing closures have been created to protect sponge reefs and the biodiversity they support (DFO 2015, 2019).

Despite the high priority of protecting biodiversity associated with sponge reefs, we have a limited under 
standing of the life histories of many organisms residing on the reefs. In particular, we do not know when many of the organisms reproduce or when larvae settle onto the reefs. For example, the exact timing of spawning and larval settlement for reef-forming glass sponges is not known, although evidence points to at least one spawning period in the winter months for sponges in the Salish Sea (Kahn et al. 2016) and potentially multiple settlement periods in Hecate Strait (Guillas et al. 2019). Knowing when reef-associated fauna (including reef-forming sponges) recruit to the sponge reefs can help guide monitoring, management, and potential restoration activities in the future.

In addition to a lack of knowledge of the life history of reef-associated fauna, it is likely that our understanding of reef-associated biodiversity is incomplete. To date the biodiversity associated with sponge reefs has largely been assessed using remote video methods because most reefs occur outside safe recreational SCUBA diving limits (i.e., deeper than 40 m; but see Krautter et al. 2001; Cook 2005; Guillas et al. 2019). While remote video surveys allow us to describe large fauna $(\geq 4 \mathrm{~cm})$ associated with the reefs, smaller organisms (hereinafter referred to as macroinvertebrate fauna), such as polychaetes and bryozoans, are typically missed. Several of the reef complexes recently discovered in Howe Sound (Clayton and Dennison 2017; Dunham et al. 2018) are significantly shallower than other known reefs (22-127 m compared to 90-300 m), occurring within safe recreational SCUBA diving limits. The discovery of these shallow reefs allowed us, for the first time, to examine macrofaunal community structure and settlement timing on a glass sponge reef in the Salish Sea using diver-deployed settlement plates.

Juvenile settlement is driven by several factors, including water flow and the surface structure and chemistry of available substrate (Rodriguez et al. 1993). Because little is known regarding the settlement requirements for glass sponges and other reefassociated fauna we used two settlement plate materials (frosted glass and ceramic clay) in order to capture a wider range of organisms. We hypothesized that frosted glass plates would attract a more diverse and abundant community as this surface approximates the surface of erect dead sponges, the primary settlement surface available on sponge reefs. We positioned the sets of plates at different heights above the benthos as a proxy for water flow, as complex benthic habitats, like sponge reefs, create a benthic boundary layer where water flow is slowed (Grant et al. 2019). Determining whether elevation above the benthos impacts the diversity of benthic invertebrates settling on the reef has implications for reef conservation as well. When human activities damage sponge reefs they de- stroy the three-dimensional structure of the reef, often crushing or toppling both live and dead sponges. If a more diverse invertebrate community settles on plates higher above the benthos, this destruction of the three-dimensional structure may have larger impacts on reef-associated biodiversity than previously reported. We hypothesized that plates located higher above the benthos would attract a more diverse and abundant settler community as water flow around these plates should be higher. Overall, the goal for this study was to describe the biodiversity of small benthic invertebrates associated with sponge reefs and determine if settler diversity is affected by plate material and/or height above the benthos. Additionally, we report the first description of larval settlement timing for several invertebrate species in the northeast Pacific.

\section{Study Area}

Our study occurred at the Halkett Point glass sponge reef in Howe Sound, Salish Sea on the southwest coast of British Columbia (BC), within the Halkett Bay Provincial Marine Park northwest of the city of Vancouver (Figure 1a). The glass sponge reef was first discovered by G. Dennison in 1996 and first formally described by Clayton and Dennison (2017). The reef was federally protected from all bottomcontact fishing activities in 2019, but at the time of our study, in 2017, fishing restrictions were not yet in place (DFO 2019). The main sponge reef occurs between 22-90 $\mathrm{m}$ on a pinnacle that is irregular in shape with a relatively flat top and gently sloping sides (Figure 1b; Clayton and Dennison 2017; DFO 2018). Glass sponge reefs are naturally patchy with areas of live, erect dead, and buried dead sponge present throughout the reef (Dunham et al. 2018). At Halkett Point sponge reef live reef-building sponges cover $4 \%$ of the reef and $40 \%$ of the reef was classified as live reef habitat (i.e., live sponges dominate the benthos; Dunham et al. 2018); 31 associated species have been documented on the reef (DFO 2018; Dunham et al. 2018). Some rocky outcroppings are found on the western side of the pinnacle.

\section{Methods}

\section{Tree design, deployment, monitoring, and retrieval}

Two trees with eight settlement plates each were constructed using a $1.5 \mathrm{~m}$ length of $20 \mathrm{~mm}$ PVC pipe (sold as $3 / 4$ inch PVC pipe) for the stem with two sets of $0.30 \mathrm{~m}$ length PVC branches extending from the top and middle portions of the stem (Figure 2a,b). Each branch was further divided into two additional branches, each supporting a $0.11 \mathrm{~m} \times 0.11 \mathrm{~m} \times 0.03 \mathrm{~m}$ settlement plate made of either ceramic clay or frosted glass. Plates were fastened to the PVC branch with a 
a

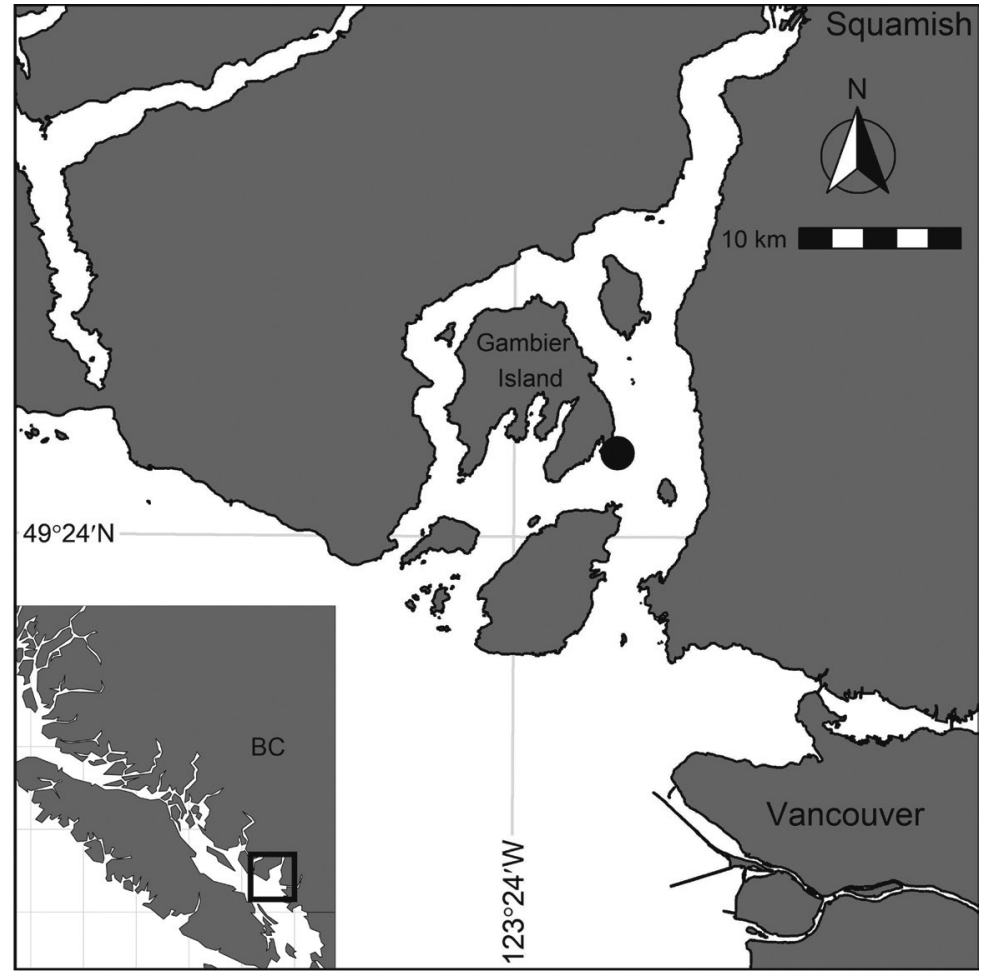

b

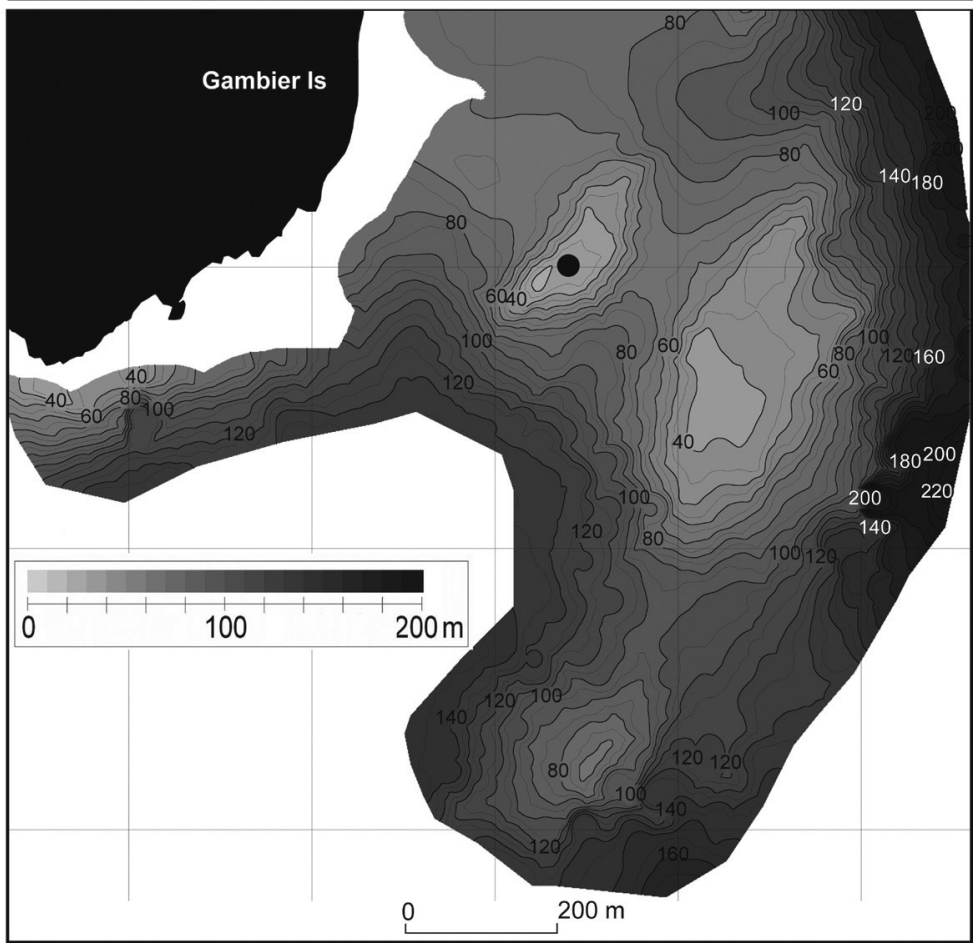

Figure 1. a. The location of the Halkett Point glass sponge reef as marked by the black dot, and b. a detailed bathymetric map of the reef area. Bathymetry contours were derived from a $3 \times 3 \mathrm{~m}$ resolution survey of the area using downwards sonar conducted by G. Dennison. The location of the settlement trees is marked on b with a black dot. 

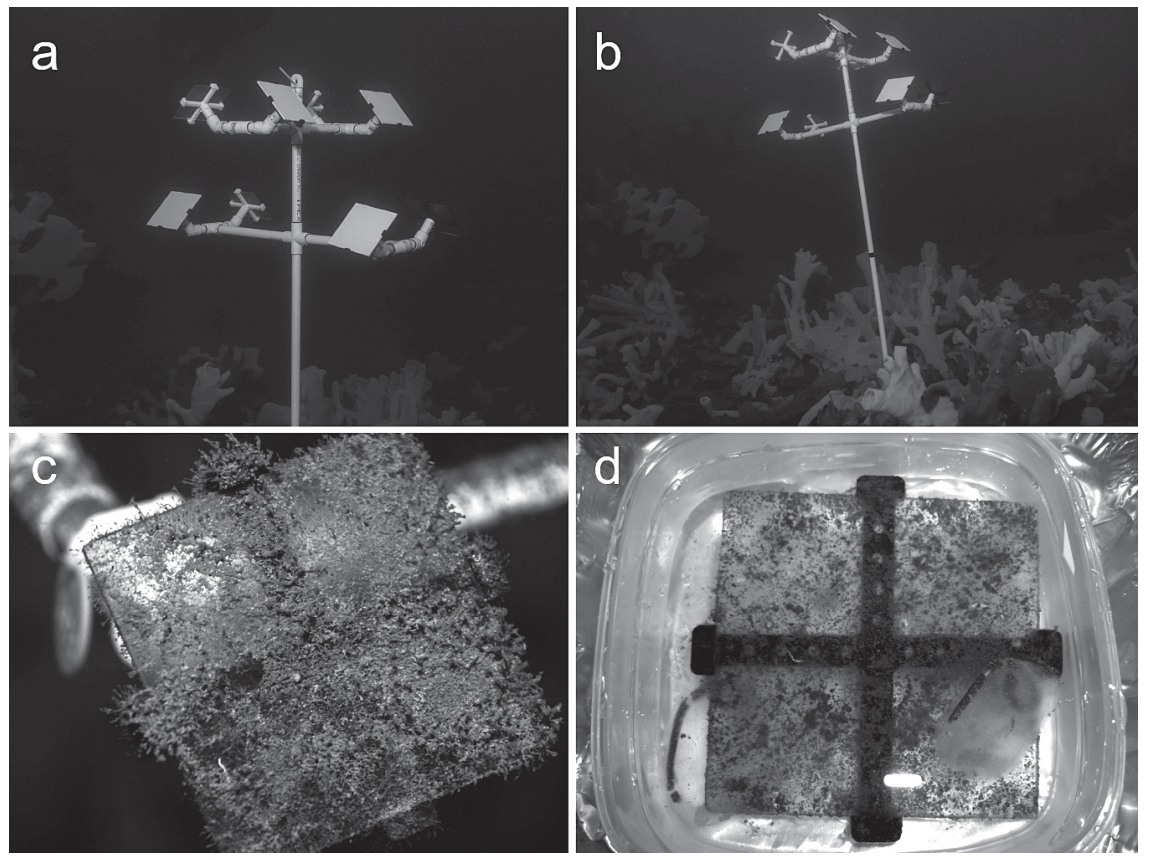

Figure 2. The settlement plate trees in situ: closeup (a) and with a landscape view (b). Plates were attached to the trees at the ends of the branches at a $45^{\circ}$ angle. c. is an example of a plate in situ and d. is a plate after retrieval. Photos: Adam Taylor (a,b), Diane Reid (c), Sheila Byers (d).

plastic bracket (Figure 2a). Each tree was designed to hold two ceramic and two glass settlement plates on each of the upper and lower branches for a total of four of each plate type; the upper and lower branches were $24 \mathrm{~cm}$ apart. The brackets holding the ceramic and glass plates were designed in SOLIDWORKS ${ }^{\circledR}$ 3D mechanical CAD software Rev 2016 (Dassault Systèmes SolidWorks Corporation, Waltham, Massachusetts, USA) and produced with a Stratasys Mojo 3D printer (Computer Aided Technology, Buffalo Grove, Illinois, USA). The bracket was designed to allow for easy removal and installation of the plates. Each set of glass and ceramic settling plates was identified with a unique tag secured to the corresponding branch of the tree.

The trees were deployed $11.8 \mathrm{~m}$ apart on 4 March 2017. Trees were installed with settlement plates attached by penetrating the stem of the tree into the soft surface layer of the reef (e.g., Figure 2b). The trees were deployed in an area next to low-density sponge (31.7 $\mathrm{m}$ depth, hereinafter tree 1) with the lower branches $\sim 0.5 \mathrm{~m}$ above the benthos and in an area next to high density sponge (at $33.5 \mathrm{~m}$ depth, hereinafter tree 2) with the lower branches $\sim 0.65 \mathrm{~m}$ above the benthos.

ATidBit ${ }^{\circledR}$ v2 (Onset Computer Corporation, Bourne, Massachusetts, USA) temperature logger was at- tached to the lower branch of each tree to record temperature every $15 \mathrm{~min}$ over the course of the study. Data from both temperature loggers were collected from 12 March to 16 August 2017; the temperature logger attached to tree 1 failed to record from 16 August 2017 to 21 April 2018 and thus only data from tree 2 were available for this time period.

Monitoring of settlement on the plates was done with macrophotography. Divers visited the site on 9 July 2017, 16 August 2017, 2 December 2017, and 8 April 2018 to photograph the settlement plates. Photos were taken in a sequence that included an initial photo of the unique identifier tag followed by photos of the frosted glass and ceramic clay settlement plate associated with each tag; photos of the entire settlement plate and of each plate's surface were taken at a greater magnification. These photos were not used in our analysis as many of the taxa that settled on the plates are difficult, if not impossible, to identify even to phylum at this level of resolution. However, for slightly larger taxa $(\geq \sim 2 \mathrm{~cm})$ these photos serve as a permanent record of plate colonization and are available for future study (e.g., Figure 2c).

Settlement plates were retrieved on 8 and 21 April 2018 after $\sim 13$ months of immersion. Two plates were recovered on 8 April to test the protocol for plate recovery; the remainder were recovered in the next 
available window of safe diving weather. Retrieval involved divers removing the brackets from the trees in situ, storing the brackets with the attached settlement plates in ambient seawater in a $870 \mathrm{~mL}$ sandwich container (LOCK\&LOCKR HPL823, Lock \& Lock, Seoul, South Korea) with a secure locking lid, and bringing them to the surface to be processed. Removal of the brackets was done by loosening a $11 \mathrm{~mm}$ nut that secured them to the tree branches. At the time of retrieval, it was discovered that tree 2 had fallen over and was leaning on a clump of adjacent sponge. The maximum duration when the tree was in this final position before retrieval was estimated to be three months based on the last observation of it standing upright. Four settlement plates were resting directly on a clump of sponge while the other four plates on the tree were not in contact with the sponge.

\section{Community sampling}

Once at the surface, the 16 containers with the individual plates were processed sequentially. Each container was placed inside a larger aluminum pan to capture any spillage of seawater as the lid was removed. Approximately three-quarters of the seawater in the container was poured through a $0.25 \mathrm{~mm}$ sieve to capture any macrofauna that had been dislodged during transport from depth to surface. These dislodged or 'mobile' macrofauna are herein referred to as flocculent. Container spillage in the aluminum catch-pan was also poured through the sieve. Photographs were taken of the top and bottom sides of the plate in a prepreservation state to assist with taxa documentation and identification (e.g., Figure 2d). The flocculent residue on the $0.25 \mathrm{~mm}$ sieve was returned to the original LOCK\&LOCKR container using pre-filtered saltwater $(0.25 \mathrm{~mm}$ sieve $)$ along with a waterproof label identifying each plate. The container was then topped up with a $30 \%$ solution of $95 \%$ ethanol and pre-filtered saltwater to anesthetize macrofauna on the plate and in the flocculent. Several hours later, the anesthetizing fluid was decanted through a $0.25 \mathrm{~mm}$ sieve, the flocculent residue on the sieve returned to the container, and the container topped up with $95 \%$ ethanol. The lid of the container was securely relocked and placed into a cooler for transport to Biologica Environmental Services, Victoria, BC (a full-service aquatic taxonomy lab) for taxonomic identification. The preservation process was repeated for each of the 16 plates. The $0.25 \mathrm{~mm}$ sieve was washed with prefiltered seawater between processing of each bracketed plate.

Biologica taxonomists processed each plate by identifying and enumerating all organisms attached to the surfaces. All organisms were identified using a combination of dissecting $(10-40 \times)$ and compound $(100-1000 \times)$ microscopes and standard taxonomic keys to species or lowest practicable level. Either total abundance data (counts) or total percent cover was provided for all organisms, including solitary and colonial taxa, found attached to the top and bottom sides of each plate. Because it is often difficult, if not impossible, to identify individuals of colonial organisms, their abundance was estimated using \% cover. Percent cover was visually estimated as the total \% cover for all colonies of a given species on a side of a plate.

Organisms $>0.25 \mathrm{~mm}$ in length associated with the flocculent material in each plate's container were identified and enumerated. Organisms found in the flocculent material were either motile organisms (unattached) or organisms that may have been dislodged from the plate surfaces during transport. Taxa richness and abundances were recorded for organisms in the flocculent material. A reference collection of 46 unique taxa from the settlement plates was preserved in $95 \%$ ethanol and is now maintained in the Marine Invertebrate Collection of the Beaty Biodiversity Museum, University of British Columbia, Vancouver, Canada.

\section{Statistical analysis}

Univariate measures of biodiversity (taxa richness and Shannon's diversity) on the plates were compared between the relative height above the benthos (lower branch versus upper branch, $n=4$ plates per tree for a total of eight plates) and plate material (ceramic clay or frosted glass, $n=4$ plates per tree for a total of eight plates) using a linear mixed effects model with tree as a random factor. Tree was included as a random factor to account for any effects due to tree placement and account for the nested structure of our study design. We did not examine the interaction between plate material and the relative height off the bottom, as this was not relevant to our hypotheses. The significance of all variables (fixed and random) was assessed using the lmerTest package in $\mathrm{R}$ version 3.6.1 (Kuznetsova et al. 2017; R Core Team 2019). All taxa associated with a single plate were pooled regardless of the side (i.e., top, bottom, or flocculent) on which they occurred. Diversity was analyzed separately for solitary and colonial organisms due to differences in how their abundance was recorded. Overall community structure was compared for all organism types using redundancy analysis (RDA) with presence-absence data. Separate RDAs were completed for both solitary and colonial animals using abundance data. For all RDA analyses the community data were transformed with a Hellinger transformation to meet the assumptions of the analysis. All RDAs included height above benthos, plate material, and tree as predictor variables. Overall RDA significance and the significance of individual axes were evaluated using analysis of variance. Taxa were con- 
sidered associated with an axis if their goodness-of-fit score was 0.5 or higher. All analyses were conducted in R (version 3.6.1; R Core Team 2019).

\section{Life history information and settlement timing}

We assumed that juvenile taxa had settled on the plates relatively recently, within the previous two months. A list was generated of all taxa that were both identified to at least the genus level and had juveniles present on the plates. For these species we searched the literature for information regarding when spawning and/or larval settlement are known to occur. We also searched for information regarding larval and juvenile duration. The search was first restricted to reports from the northeast Pacific and then expanded to a global search. For species where information was found, we compared the published information with our findings.

\section{Results}

Water temperature differed significantly between the settlement trees during the period from March to August 2017 (paired $t$-test, $t_{15102}=153.91$, $P<0.0001)$ : tree 1 was in slightly warmer conditions (mean $9.15^{\circ} \mathrm{C}$, range $8.25-10.96^{\circ} \mathrm{C}$ ) compared to tree 2 (mean $9.06^{\circ} \mathrm{C}$, range $8.17-10.76^{\circ} \mathrm{C}$ ). Overall temperature range recorded in this study was $8.02-10.96^{\circ} \mathrm{C}$.

\section{Qualitative description of the invertebrate community}

Overall, 70 taxa from 10 phyla were observed on the settlement plates $(n=16$, including the top, bottom, and flocculent material for all plates). Most taxa (58, or $82.9 \%$ ) were found on fewer than $50 \%$ of the plates and 28 species $(40 \%)$ were found on a single plate. Three species were found on all 16 plates: $A l$ cyonidium cf. polyoum (no common name, Bryozoa), Irregular Calcareous Tubeworm (Crucigera irregularis, Annelida), and Western Calcareous Tubeworm (Pseudochitinopoma occidentalis, Annelida). A full list of taxa identified on the plates can be found in Table S1. Annelids were by far the most taxa-rich phylum on our plates, with 23 taxa observed, followed by Cnidaria with 12 taxa observed, then by Bryozoa and Mollusca with 10 taxa each. A single taxon was observed for three phyla: Nemertea, Platyhelminthes, and Porifera. Despite having a single taxon representative, both Nemertea and Porifera were found on multiple plates (two and seven plates, respectively). Fewer taxa were observed on the tops of plates (33) than either in the flocculent material (47) or on the bottom side (49) of the plates. When only considering taxa that were observed more than once (i.e., multiple individuals or distinct colonies were seen) several taxa were found to occur on a single side of the plate. There were four taxa, each from a different phylum, that occurred only on the bottom sides of plates. These were Stomatopora sp. (Bryozoa), Tiny White Tunicate (Bathypera feminalba, Chordata [Tunicata]), Epiactis sp. (Cnidaria) and Doridacea indet. (Mollusca). A single taxon from Arthropoda, Balanomorpha indet., was found to only occur on the tops of the plates. Eleven taxa from four phyla (Annelida, Cnidaria, Mollusca, and Nemertea) were found only in the flocculent material (marked with a star in Table S1). All taxa found only in the flocculent material are mobile species. Regardless of the taxonomic level of organization examined, the bottom sides of plates were the most taxarich (Figure S1). Contrastingly, the flocculent material was consistently more diverse when considering solitary organisms (Figure S2) while there was no difference between plate sides in the diversity of colonial organisms (Figure S3; no colonial organisms were recorded in the flocculent material).

Effects of substrate and relative height above the benthos on invertebrate community composition and structure

Taxa richness on individual plates ranged from 11 to $25(17.69 \pm 4.00$, mean $\pm \mathrm{SD})$. There was no difference in species richness attributable to the relative height off the benthos $\left(F_{1,12}=0.16, P=0.70\right)$, the plate material $\left(F_{1,12}=0.07, P=0.79\right)$, or the tree the plate was attached to $\left(\chi_{1}^{2}=0.54, P=0.46\right)$. Similarly, the diversity of both solitary and colonial organisms were not influenced by relative height off the benthos (solitary: $F_{1,12}=0.52, P=0.48$; colonial: $F_{1,12}=0.12, P=$ 0.73 ), plate material (solitary: $F_{1,12}=1.79, P=0.21$; colonial: $\left.F_{1,12}=3.62, P=0.08\right)$, or the tree to which the plate was attached (solitary: $\chi_{1}^{2}=2.19, P=0.14$; colonial: $\left.\chi_{1}^{2}=2.43, P=0.12\right)$. When the entire community was examined as a whole using presence-absence data and relative height off the benthos, plate material, and the tree the plate was attached to as explanatory variables, the RDA had an $R^{2}$ adj of 0.14 and one significant axis $\left(F_{1,12}=3.41, P=0.001\right)$. The first and only significant axis separated the communities occurring on the two trees (Figure 3a). The barnacle Balanomorpha indet., the nudibranch Aeolidioidea indet., and the hydrozoan Clytia hemisphaerica were strongly associated with tree 2 . When solitary taxa were analyzed separately, the same predictor variables resulted in an $R_{\text {adj }}^{2}$ of 0.09 and one significant axis $\left(F_{1,12}=2.53, P=0.02\right)$. The significant axis again corresponded with the tree to which the plates were attached (Figure 3b) and the barnacle Balanomorpha indet. and the nudibranch Aeolidioidea indet. were associated with tree 2 . For colonial organisms, the RDA had an $R^{2}$ adj of 0.39 and a single significant axis $\left(F_{1,12}\right.$ $=11.25, P=0.002)$, which again corresponded with the tree to which the plates were attached (Figure $3 \mathrm{c}$ ). The hydrozoan $C$. hemisphaerica was associated with 

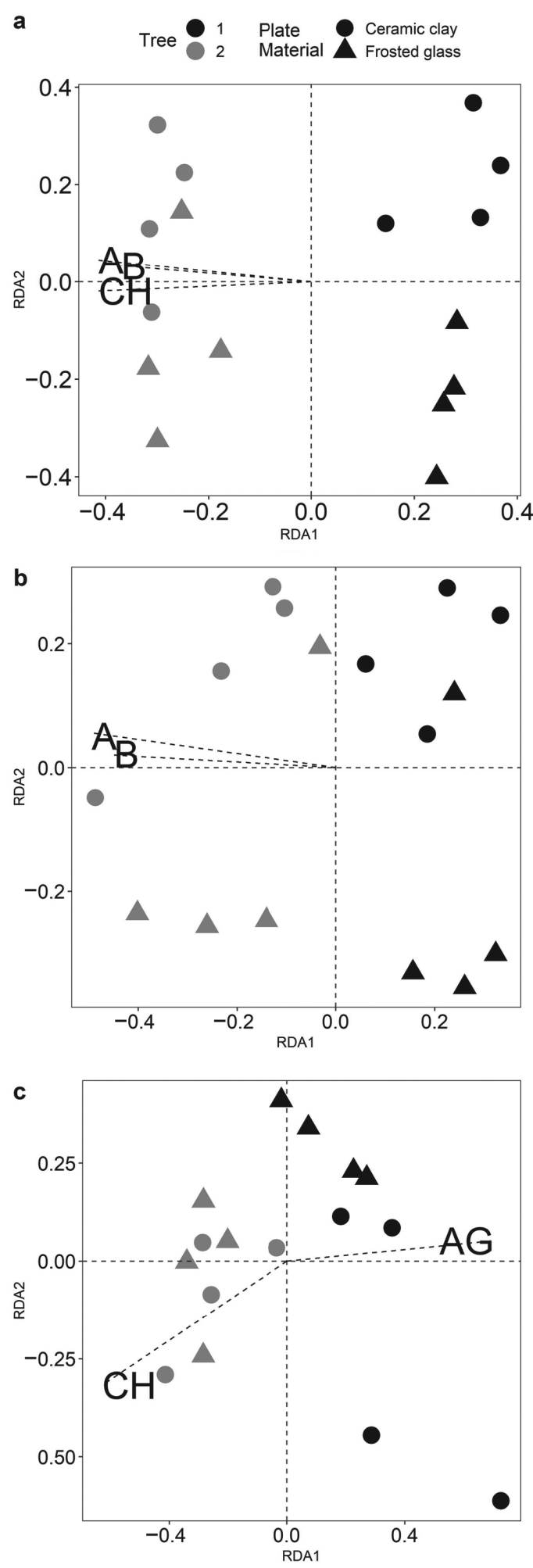

tree 2 while the bryozoan Amathia gracilis was associated with tree 1 .

\section{Settlement timing}

Juveniles of 17 taxa identifiable at the species or genus level were found on the plates at the time of collection (April 2018; Table 1). Of these, we were able to find information regarding spawn timing or larval settlement periods in the literature (for either the species we observed or members of the same genus) for 15 taxa. In most cases the information regarding reproductive timing was not based on studies from the northeastern Pacific. Regardless, the reported spawning or larval settlement timing generally agreed with our findings (Table 1). In four cases, Paleanotus bellis, Pododesmus sp., Prionospio (Minuspio) multibranchiata, and Prionospio (Minuspio) sp., our observation of juveniles on the plates in April does not correspond to spawning seasons reported in the literature. In all cases we observed juveniles of these species earlier than reported spawning periods. For $P$. bellis we found reports of spawning occurring between May and November with juvenile settlement occurring approximately three weeks later (Rasmussen 1956; Bhaud et al. 1987; Table 1), but we recorded juveniles in April. Similarly, for Pododesmus sp. our findings suggest spawning occurred earlier than has been previously reported, as Drozdov et al. (2009) reported spawning occurring in the Sea of Japan in May and then again from August to October. We did not find any reports on larval duration for this genus. In Atlantic Canada members of the Prionospio genus were found spawning between May and August (Lacalli 1981). It should be noted that Prionospio patagonica larvae were found in October, November, and March in Chile (Radashevsky et al. 2006), timing that corresponds seasonally to the appearance of juveniles on our plates in April, because Chile is in the southern hemisphere. In two cases, Lanassa venusta venusta and Proclea sp., we were unable to find any reports of spawn timing in the literature for species more closely related than the family level (i.e., in a different genus within the same family). For these two species there are reports of reproductive timing

Figure 3. Biplot of the three redundancy analyses conducted using a. presence-absence data from the entire community, b. abundance data for solitary, and c. colonial organisms on the settlement plates. Species displayed were strongly associated with one or both of the axes displayed (goodness-of-fit of at least 0.50 ). There are significant differences between the communities found on the two trees. Plate material did not significantly influence community structure. The taxa names are abbreviated on the figure panels so that $\mathrm{A}=$ Aeolidioidea indet. (nudibranch), $\mathrm{AG}$ = Amathia gracilis (Bryozoan), $\mathrm{B}=$ Balanomorpha indet. (barnacle), and $\mathrm{CH}=$ Clytia hemisphaerica (hydrozoan). 


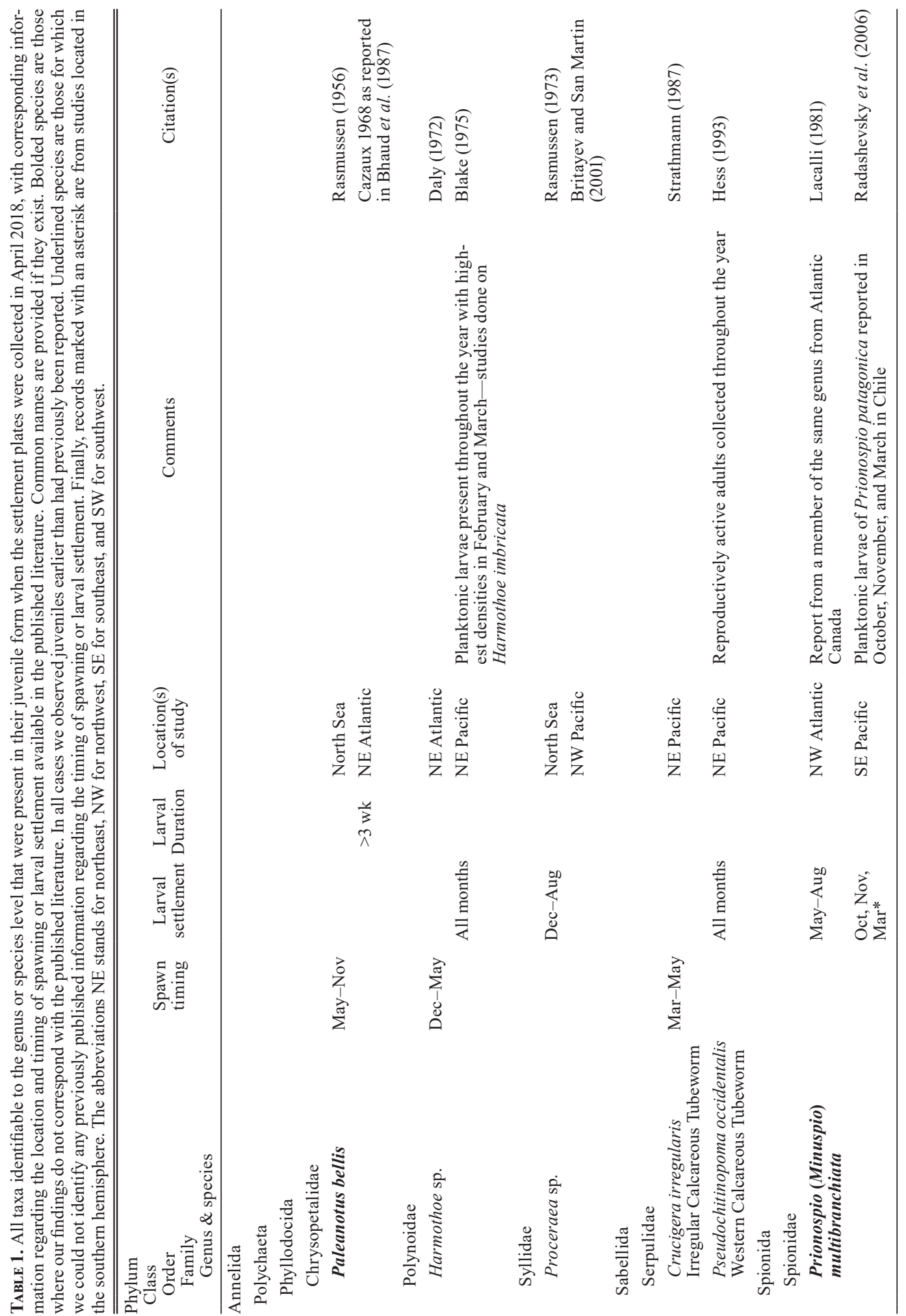




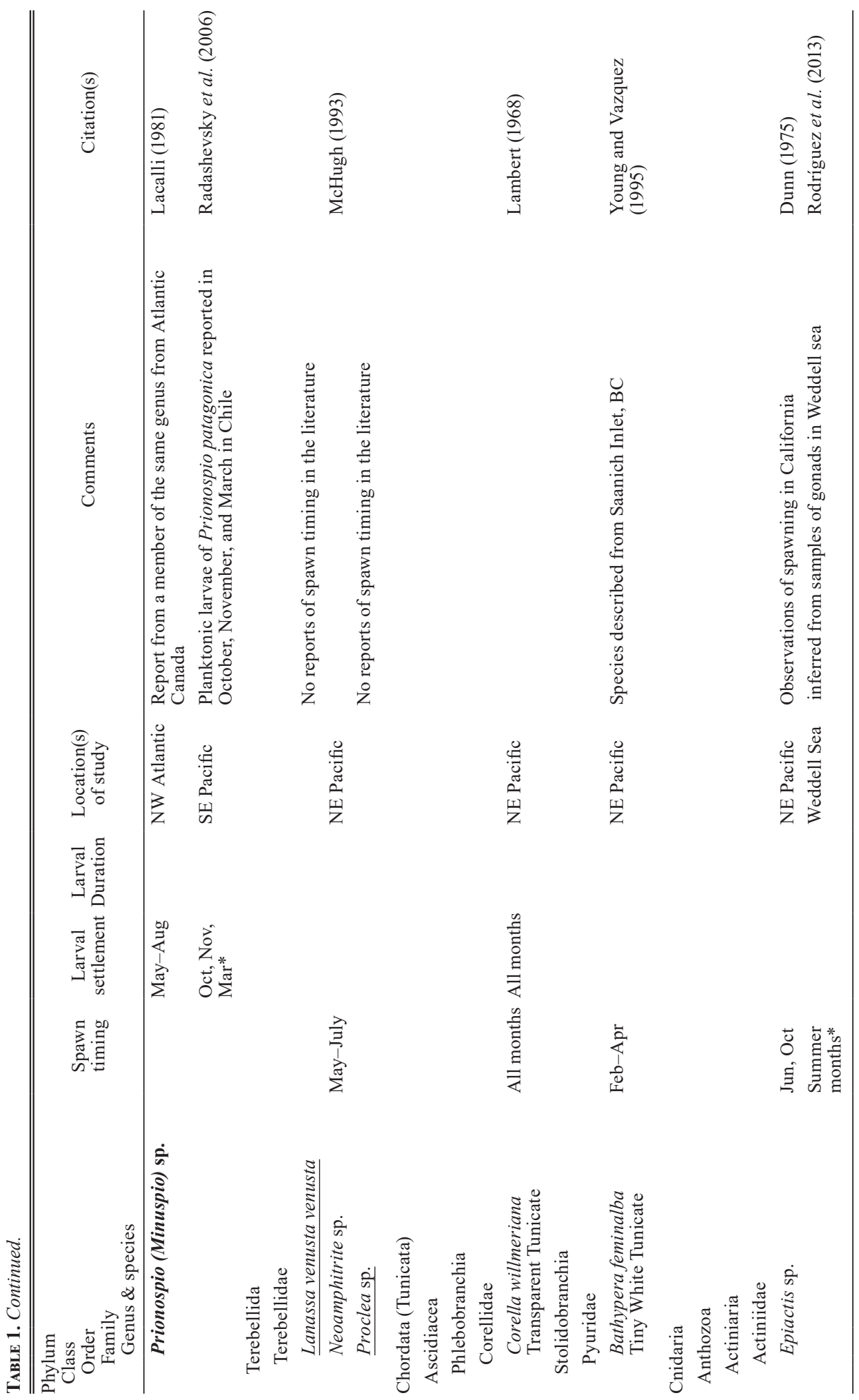




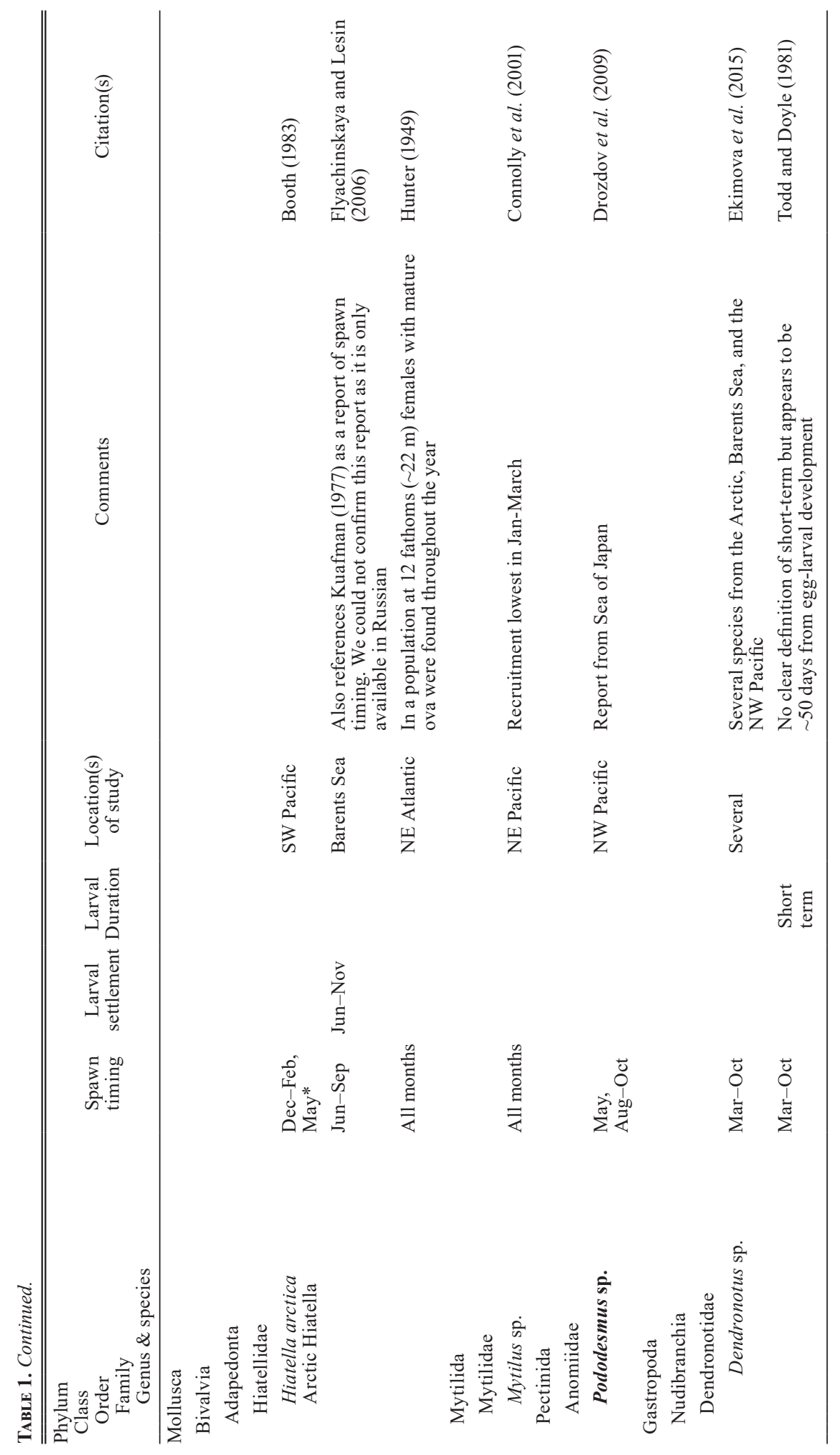


for closely related genera. However, our search was restricted to members of the same genus and therefore we did not include this information in Table 1. For the 15 species where we could find reports of the timing of reproduction and/or larval settlement, we were unable to find reports from the northeast Pacific for seven species. Therefore, our contribution represents the first clues to larval settlement timing in the northeast Pacific for nine species.

\section{Non-indigenous species}

None of the organisms identified to species in our study are known to be non-indigenous in BC. We recorded taxonomic relatives of non-indigenous species in $\mathrm{BC}$ with similar life histories (e.g., Eusyllis blomstrandi and Eusyllis habei are members of the same genus as Eusyllis japonica, a non-indigenous species in BC; Lu et al. 2007). It should be noted that E. blomstrandi may be part of a cryptic species complex in the northeastern Pacific (Kudenov et al. 1995).

\section{Discussion}

An important step in the processes of ensuring effective ecosystem-level conservation is building a thorough understanding of the systems we are attempting to protect. Sponge reefs are a high conservation priority because of their global rarity, slow growth and low recovery potential, and the biodiversity they support (Cook et al. 2008; Chu and Leys 2010; Kahn et al. 2015, 2016; Dunham et al. 2018). Previous work using remote video surveys has provided a thorough description of the larger fauna occurring on the reefs, yet a gap remained in our understanding of small taxa not detectable using remote methods. Here we present the first report of invertebrate settlement on a sponge reef in the Salish Sea and increase our understanding of biodiversity on sponge reefs.

There have been three previous studies on small macroinvertebrate fauna on sponge reefs in BC. However, all of these studies have occurred on the reefs in Hecate Strait (over $600 \mathrm{~km}$ to the northwest) and have studied animals found in cores or settled on sponges collected from the reef. Krautter et al. (2001) collected cores from the reefs in Hecate Strait and described a macroinvertebrate faunal community dominated by polychaetes and bryozoans, consistent with what we found in Howe Sound. Cook (2005) described the polychaete community on sponge reefs from cores taken within and around the Hecate Strait sponge reefs. They found 105 species of polychaetes from 27 families. We identified 22 polychaetes from nine families (Table S1). Interestingly we did not find any species reported in Cook (2005) and only two genera and four families were found in both studies. The Hecate Strait reefs and the reef in our study are separated by over $600 \mathrm{~km}$ and there is over a 100 $\mathrm{m}$ difference in the depth, those in Howe Sound being shallower. Therefore, it may be unsurprising that the taxa found in the two studies overlapped so little. Cook (2005) found a statistically significant difference in the polychaete communities on sponge reefs when compared to non-reef habitat immediately adjacent to the reefs. In the future it may be interesting to repeat a study similar to ours but with settlement plate trees located at similar depth in the off-reef habitat.

In a recent study, Guillas et al. (2019) looked at the macrofauna settled on $F$. occa individuals collected from a Hecate Strait reef. Despite the fact that their study and ours had only one species in common (Arctic Hiatella, Hiatella arctica) the overall community structure was similar with a community composed largely of sponges, bryozoans, molluses, and polychaetes. However, our study documented two new phyla occurring on sponge reefs (Nemertea and Platyhelminthes) and expanded our knowledge of the settlement timing of invertebrates in this system. While our study failed to document any reef-building sponge settlement, Guillas et al. (2019), who collected reef-building sponges with both live and dead portions, found many small reef-building sponges potentially representing many settlement pulses over the past year. This is consistent with observations made by Kahn et al. (2016), who observed evidence of multiple reproductive events within a year on the Galiano Ridge sponge reef in the Salish Sea. While it is still unclear what environmental cues lead to spawning in reef-building glass sponges, it is likely, given other studies that report evidence of multiple spawning events within a calendar year, that reef-building sponges spawned while our settlement plates were deployed, but larvae did not recruit to the plates.

We did not find any difference in taxa richness, diversity, or community structure associated with the relative height above the benthos. In other words, height above benthos did not appear to structure the community on our settlement plates. This may have been for several reasons. First, the two trees were pushed into the substrate to different depths so that the branches were at 0.5 (tree 1), 0.65 (tree 2), 0.74 (tree 1), and $0.89 \mathrm{~m}$ (tree 2) above the benthos. If the data are reanalyzed so that actual height above benthos, rather than relative height above benthos, is included as a predictor variable the conclusions are still the same. A second reason is that a $0.24 \mathrm{~m}$ difference in height between the two branches is not large, particularly considering that sponges on BC's sponge reefs can often grow to be over $1 \mathrm{~m}$ tall (Conway et al. 2005). However, in other systems, such as seagrass beds, similar height differences have been found to influence survival, and therefore community structure, 
of invertebrates (Pohle et al. 1991). Plate material similarly had no impact on taxa richness, diversity, or community structure. It is possible that both plate materials presented too similar a surface to influence community structure.

Although we did not test for it statistically, we did find that the side of the settlement plate was an important factor influencing taxa richness and diversity. Many marine invertebrates have a pelagic portion of their larval life history during which they are photosensitive, meaning exposure to light influences their behaviour (Thorson 1964). The vast majority of photosensitive larvae become photonegative, or move away from light, as they begin to settle out of the water column and into the benthic system (Thorson 1964). This behaviour often results in larvae settling onto the undersides of available surfaces as these are the surfaces with the lowest light levels (Thorson 1964), which is consistent with our findings. However, light levels are consistently low at our study site and further research would be necessary to determine if this behaviour is the cause of the patterns we observed. The high richness and diversity of taxa found in the flocculent material is also not surprising; these taxa were overwhelmingly motile. Other settlement plate studies, with sampling protocols that allowed for the capture and enumeration of motile taxa, have similarly reported high diversity in this group (Gartner 2010). Perhaps more surprising was the consistent difference in community between the two trees. One of the trees (tree 2) was toppled over at some point in the last three months of our study, it is possible that this led to the differences we observed as there was a significant difference in the total abundance of solitary taxa between the two trees $\left(t_{12.51}=-2.71, P=\right.$ 0.02). Additionally, we did observe a small, but statistically significant difference in the water temperatures recorded at each tree in the beginning of the study. While it is unlikely that this small difference in temperature would drive the differences in diversity, it may be indicative of an environmental gradient present within the sponge reef that relates to water movement and sedimentation and thus, likely, larval dispersal within the sponge reef. It is also possible that the difference in surrounding reef-building sponge abundance affected local fine-scale currents and influenced the species settling on each tree. Further study is warranted to investigate environmental gradients and the importance of local fine-scale current patterns within sponge reefs and how these relate to larval settlement and biodiversity patterns.

This is the first published settlement plate study at these depths in BC (31.7-33.5 m). Consequently, the species found on our plates largely differed from those in other, shallower, settlement plate studies in BC, but the overall community structure observed was similar with polychaetes, hydroids, and bryozoans being prevalent (Greene and Schoener 1982; Greene et al. 1983; Gartner 2010). One species we observed, L. v. venusta (phylum Annelida), is reported to be commensal with pagurids (hermit crabs; Hoberg et al. 1982), which have been observed on sponge reefs in the Salish Sea (Dunham et al. 2018). Interestingly, we did not observe any plumose anemone (Metridium) species settling on the plates despite the fact that they are a common member of settlement plate communities in BC (Greene and Schoener 1982; Greene et al. 1983; Gartner 2010) and are commonly observed around sponge reefs in the area (Dunham et al. 2018). The presence of predators can significantly influence the development of fouling communities (Nydam and Stachowicz 2007). While the majority of the species we observed were filter-feeders, we did collect several predatory species including a number of polychaetes, a nudibranch, and some parasitic species. For example, members of the genus Proceraea (phylum Annelida) have been reported as predators and parasites of bryozoans, sponges, ascidians, echinoderms, cnidarians, and decapods (Martín and Britayev 1998). Consequently, the presence of predatory polychaetes and nudibranchs on our plates may have prevented us from detecting the settlement of some common members of the invertebrate community. However, it should be noted that there were records of unidentified Actiniaria and Anthozoa juveniles from four plates. It is possible that these may have been Metridium juveniles. Future work is needed to fully unravel processes determining macroinvertebrate community development within sponge reefs.

We found juveniles identifiable to at least the genus level from four phyla present on our settlement plates (Annelida, Chordata [Tunicata], Cnidaria, and Mollusca; Table 1). Of the 17 unique taxa that we observed as juveniles we could find records of the timing of spawning and/or larval settlement for 15. Of these 15 taxa, eight had either spawn or larval settlement times reported in studies in the northeast Pacific and only one species had been studied in BC. Our observations of juveniles corresponded with the published timing of spawning or larval settlement for all taxa in studies conducted in the northeast Pacific. To the best of our knowledge our study is the first to elucidate potential spawn timing in L. v. venusta and a Proclea species. Members of this family are reported to spawn anytime throughout the year and display a wide range of life history strategies (McHugh 1993). Despite the wide variation in reproductive strategies in this family, all species seem to have a relatively short planktonic larval duration period (0-7.5 days; McHugh 1993 and references therein). Consequently, we can infer that spawning likely occurred in these 
species in the weeks leading up to plate collection. Overall, over $51 \%$ of the individual organisms we observed, across all plates and taxa, were juveniles. The high number of juveniles on our settlement plates at the time of collection corresponds well with the hypothesis that many invertebrates in coastal BC waters spawn in the spring (Gartner 2010).

Although we did not have any reef-building sponges recruit to our settlement plates, continued settlement plate deployments focussed on testing different settlement materials and placement within the reefs could help fill important knowledge gaps on the factors influencing reef-building sponge recruitment. Additionally, continued settlement plate deployment could serve as an important monitoring tool for early detection of aquatic invasive species. Overall, our study helps to improve our understanding of biodiversity on sponge reefs.

\section{Author Contributions}

Conceptualization: S.K.A., S.B., A.D., G.D., and L.M.; Methodology: S.K.A., S.B., A.D., G.D., and L.M.; Investigation: S.B., G.D., and L.M.; Formal Analysis: S.K.A.; Writing - Original Draft: S.K.A.; Writing - Review \& Editing: S.K.A., S.B., A.D., G.D., and L.M.; Funding Acquisition: A.D.

\section{Acknowledgements}

We would like to thank the Marine Life Sanctuaries Society of British Columbia (BC) and the Underwater Council of $\mathrm{BC}$ divers who volunteered their time for this project: Team Photographers: Deirdre McCracken, Diane Reid, Chris Straub, and Adam Taylor; Installation and retrieval divers: Meagen Abele, Brendan Andresen, Fabiola Ruiz Aguilar, Philippe Beaudry, Bobby Chan, Scott Dowd, Marley Heron, Rahim Kaba, Cassandra Konecny, Viviana Lee, Lauren Liggan, Scott Meixner, Amy Morgan-Young, Tanya Prinzing, Bartek (Bart) Radziej, and Joshua Teerling. The Department of Fisheries and Oceans' National Conservation Plan contributed funding to this project.

\section{Literature Cited}

Bhaud, M., C. Cazaux, C. Russell, and M. Lefevre. 1987. Description and identification of polychaete larvae: their implications in current biological problems. Oceanis 13: 595-753

Blake, J.A. 1975. The larval development of polychaeta from the northern California Coast. III eighteen species of errantia. Ophelia 14: 23-84. https://doi.org/10.1080/0 0785236.1975.10421969

Booth, J.D. 1983. Studies on twelve common bivalve larvae, with notes on bivalve spawning seasons in New Zealand. New Zealand Journal of Marine and Freshwater Research 17: 231-265. https://doi.org/10.10 80/00288330.1983.9516001

Britayev, T.A., and G.L.A. San Martin. 2001. Description and life-history traits of a new species of Proceraea with larvae infecting Abietinaria turgida (Polychaeta, Syllidae \& Hydrozoa, Sertulariidae). Ophelia 54: 105113. https://doi.org/10.1080/00785236.2001.10409458

Chu, J., and S.P. Leys. 2010. High resolution mapping of community structure in three glass sponge reefs (Porifera, Hexactinellida). Marine Ecology Progress Series 417: 97-113. https://doi.org/10.3354/meps08794

Chu, J.W., M. Maldonado, G. Yahel, and S.P. Leys. 2011. Glass sponge reefs as a silicon sink. Marine Ecology Progress Series 441: 1-14. https://doi.org/10.3354/meps 09381

Clayton, L., and G. Dennison. 2017. Inexpensive video drop-camera for surveying sensitive benthic habitats: applications from glass sponge (Hexactinellida) reefs in Howe Sound, British Columbia. Canadian FieldNaturalist 131: 46-54. https://doi.org/10.22621/cfn.v131 i1.1783

Connolly, S.R., B.A. Menge, and J. Roughgarden. 2001. A latitudinal gradient in recruitment of intertidal invertebrates in the northeast Pacific Ocean. Ecology 82: 1799-1813. https://doi.org/10.2307/2680048

Conway, K., J. Barrie, W. Austin, and J. Luternauer. 1991. Holocene sponge bioherms on the western Canadian continental shelf. Continental Shelf Research 11: 771790. https://doi.org/10.1016/0278-4343(91)90079-L

Conway, K.W., J.V. Barrie, and M. Krautter. 2005. Geomorphology of unique reefs on the western Canadian shelf: sponge reefs mapped by multibeam bathymetry. Geo-Marine Letters 25: 205-213. https://doi.org/10.1007/ s00367-004-0204-z

Cook, S.E. 2005. Ecology of the hexactinellid sponge reefs on the western Canadian continental shelf. M.Sc. thesis, University of Victoria, Victoria, British Columbia, Canada.

Cook, S.E., K.W. Conway, and B. Burd. 2008. Status of the glass sponge reefs in the Georgia Basin. Marine Environmental Research 66: S80-S86. https://doi.org/ 10.1016/j.marenvres.2008.09.002

Daly, J.M. 1972. The maturation and breeding biology of Harmothoë imbricata (Polychaeta: Polynoidae). Marine Biology 12: 53-66. https://doi.org/10.1007/bf00347429

DFO (Fisheries and Oceans Canada). 2015. Fishery Notice FN0415. Accessed 10 January 2019. http://wwwops2.pac.dfo-mpo.gc.ca/fns-sap/index-eng.cfm?pg= view_notice $\& D O C \_I D=183964 \& I D=a l l$.

DFO (Fisheries and Oceans Canada). 2018. Glass Sponge aggregations in Howe Sound: locations, reef status, and ecological significance assessment. DFO Canadian Science Advise Secretariat Science Response 2018/032. Fisheries and Oceans Canada, Pacific Region, Canada.

DFO (Fisheries and Oceans Canada). 2019. Fishery Notice FN0205. Accessed 1 May 2019. https://www-ops2. pac.dfo-mpo.gc.ca/fns-sap/index-eng.cfm?pg=view notice \&DOC_ID $=219517 \&$ ID $=$ all.

Drozdov, A.L., S.N. Sharina, and S.A. Tyurin. 2009. Sperm ultrastructure in representatives of six bivalve families from Peter the Great Bay, Sea of Japan. Russian Journal of Marine Biology 35: 236-241. https://doi.org/ 10.1134/s1063074009030079

Dunham, A., S.K. Archer, S.C. Davies, L.A. Burke, J. 
Mossman, J.R. Pegg, and E. Archer. 2018. Assessing condition and ecological role of deep-water biogenic habitats: glass sponge reefs in the Salish Sea. Marine Environmental Research 141: 88-99. https://doi.org/10. 1016/j.marenvres.2018.08.002

Dunham, A., J.R. Pegg, W. Carolsfeld, S.C. Davies, I. Murfitt, and J. Boutillier. 2015. Effects of submarine power transmission cables on a glass sponge reef and associated megafaunal community. Marine Environmental Research 107: 50-60. https://doi.org/10. 1016/j.marenvres.2015.04.003

Dunn, D.F. 1975. Reproduction of the externally brooding sea anemone Epiactis prolifera Verrill, 1869. Biological Bulletin 148: 199-218. https://doi.org/10.2307/1540543

Ekimova, I., T. Korshunova, D. Schepetov, T. Neretina, N. Sanamyan, and A. Martynov. 2015. Integrative systematics of northern and Arctic nudibranchs of the genus Dendronotus (Mollusca, Gastropoda), with descriptions of three new species. Zoological Journal of the Linnean Society 173: 841-886. https://doi.org/10.1111/ zoj. 12214

Flyachinskaya, L.P., and P.A. Lesin. 2006. Using 3D reconstruction method in the investigations of Bivalvia larval development (by the example of Hiatella arctica L.). Proceedings of the Zoological Institute of the Russian Academy of Science 310: 45-50.

Gartner, H. 2010. Subtidal invertebrate fouling communities of the British Columbian coast. M.Sc. thesis, University of Victoria, Victoria, British Columbia, Canada.

Grant, N., E. Matveev, A.S. Kahn, S.K. Archer, A. Dunham, R.J. Bannister, D. Eerkes-Medrano, and S.P. Leys. 2019. Effect of suspended sediments on the pumping rates of three species of glass sponge in situ. Marine Ecology Progress Series 615: 79-100. https://doi.org/10. 3354/meps12939

Greene, C.H., and A. Schoener. 1982. Succession on marine hard substrata: a fixed lottery. Oecologia 55: 289297. https://doi.org/10.1007/bf00376914

Greene, C.H., A. Schoener, and E. Corets. 1983. Succession on marine hard substrata: the adaptive significance of solitary and colonial strategies in temperate fouling communities. Marine Ecology Progress Series 13: 121129. https://doi.org/10.3354/meps013121

Guillas, K.C., A.S. Kahn, N. Grant, S.K. Archer, A. Dunham, and S.P. Leys. 2019. Settlement of juvenile glass sponges and other invertebrate cryptofauna on the Hecate Strait glass sponge reefs. Invertebrate Biology 138: e12266. https://doi.org/10.1111/ivb.12266

Hess, H.C. 1993. The evolution of parental care in brooding spirorbid polychaetes: the effect of scaling constraints. American Naturalist 141: 577-596. https://doi.org/10.10 $86 / 285492$

Hoberg, M.K., S.G. McGee, and H.M. Feder. 1982. Polychaetes and amphipods as commensals with pagurids from the Alaska shelf. Ophelia 21: 167-179. https://doi. org/10.1080/00785326.1982.10426585

Hunter, W.R. 1949. The structure and behaviour of Hiatella gallicana (Lamarck) and $H$. arctica (L.), with special reference to the boring habit. Proceedings of the Royal Society of Edinburgh, Section B: Biology 63: 271-289. https://doi.org/10.1017/S0080455X00011930
Kahn, A.S., J.W.F. Chu, and S.P. Leys. 2018. Trophic ecology of glass sponge reefs in the Strait of Georgia, British Columbia. Scientific Reports 8: 756. https://doi. org/10. 1038/s41598-017-19107-X

Kahn, A.S., L.J. Vehring, R.R. Brown, and S.P. Leys. 2016. Dynamic change, recruitment and resilience in reef-forming glass sponges. Journal of the Marine Biological Association of the United Kingdom 96: 429436. https://doi.org/10.1017/S0025315415000466

Kahn, A.S., G. Yahel, J.W. Chu, V. Tunnicliffe, and S.P. Leys. 2015. Benthic grazing and carbon sequestration by deep-water glass sponge reefs. Limnology and Oceanography 60: 78-88. https://doi.org/10.1002/1no. 10002

Krautter, M., K.W. Conway, J.V. Barrie, and M. Neuweiler. 2001. Discovery of a "Living Dinosaur": globally unique modern hexactinellid sponge reefs off British Columbia, Canada. Facies 44: 265-282. https:// doi.org/10.1007/bf02668178

Kudenov, J., L. Harris, J. Blake, B. Hilbig, and P. Scott. 1995. Taxonomic atlas of the benthic fauna of the Santa Maria Basin and Western Santa Barbara channel. No. 5. Santa Barbara Museum of Natural History, Santa Barbara, California, USA.

Kuznetsova, A., P.B. Brockhoff, and R.H.B. Christensen. 2016. 1merTest: tests in linear mixed effects models. R package version 2.0-30. Accessed 8 April 2020. https:// CRAN.R-project.org/package $=$ lmerTest.

Lacalli, T. 1981. Annual spawning cycles and planktonic larvae of benthic invertebrates from Passamaquoddy Bay, New Brunswick. Canadian Journal of Zoology 59: 433-440. https://doi.org/10.1139/z81-063

Lambert, G. 1968. The general ecology and growth of a solitary ascidian, Corella willmeriana. Biological Bulletin 135: 296-307. https://doi.org/10.2307/1539783

Lu, L., C. Levings, and G. Piercey. 2007. Preliminary investigation on aquatic invasive species of marine and estuarine macrobenthic invertebrates on floating structures in five British Columbia harbours. Canadian Manuscript Report of Fisheries and Aquatic Sciences 2814. Vancouver, British Columbia, Canada.

Maldonado, M., R. Aguilar, R.J. Bannister, J.J. Bell, K.W. Conway, P.K. Dayton, C. Díaz, J. Gutt, M. Kelly, E.L.R. Kenchington, S.P. Leys, S.A. Pomponi, H.T. Rapp, K. Rützler, O.S. Tendal, J. Vacelet, and C.M. Young. 2016. Sponge grounds as key marine habitats: a synthetic review of types, structure, functional roles, and conservation concerns. Pages 1-39 in Marine Animal Forests: The Ecology of Benthic Biodiversity Hotspots. Edited by S. Rossi, L. Bramanti, A. Gori, and C. Orejas Saco del Valle. Springer International Publishing, Cham, Switzerland. https://doi.org/10.1007/ 978-3-319-17001-5 24-1

Martín, D., and T.A. Britayev. 1998. Symbiotic polychaetes: review of known species. Oceanography and Marine Biology: an Annual Review 36: 217-340.

McHugh, D. 1993. A comparative study of reproduction and development in the polychaete family Terebellidae. 
Biological Bulletin 185: 153-167. https://doi.org/10.23 $07 / 1541996$

Nydam, M., and J.J. Stachowicz. 2007. Predator effects on fouling community development. Marine Ecology Progress Series 337: 93-101. https://doi.org/10.3354/me ps337093

Pohle, D.G., V.M. Bricelj, and Z. García-Esquivel. 1991. The eelgrass canopy: an above-bottom refuge from benthic predators for juvenile bay scallops Argopecten irradians. Marine Ecology Progress Series 74: 47-59. https://doi.org/10.3354/meps074047

R Core Team. 2019. R: a language and environment for statistical computing. R Foundation for Statistical Computing, Vienna, Austria.

Radashevsky, V.I., M. Díaz, and C. Bertrán. 2006. Morphology and biology of Prionospio patagonica (Annelida: Spionidae) from Chile. Journal of the Marine Biological Association of the United Kingdom 86: 61-69. https://doi.org/10.1017/S0025315406012860

Rasmussen, E. 1956. The reproduction and larval development of some polychaetes from Isefjord, with some faunistic notes. Biologiske Meddelelser udgivet af Det Kongelige Danske Videnskabernes Selskab 23: 1-90.

Rasmussen, E. 1973. Systematics and ecology of the Isefjord marine fauna (Denmark). Ophelia 11: 1-507. https:// doi.org/10.1080/00785326.1973.10430115

Rodriguez, S.R., F.P. Ojeda, and N.C. Inestrosa. 1993. Settlement of benthic marine invertebrates. Marine Ecology Progress Series 97: 193-207. https://doi.org/ 10.3354/ meps097193
Rodríguez, E., C. Orejas, P.J. López-González, and J.M. Gili. 2013. Reproduction in the externally brooding sea anemone Epiactis georgiana in the Antarctic Peninsula and the Weddell Sea. Marine Biology 160: 67-80. https://doi.org/10.1007/s00227-012-2063-x

Stone, R.P., K.W. Conway, D. Csepp, and J. Barrie. 2014. The boundary reefs: glass sponge (Porifera: Hexactinellidae) reefs on the international border between Canada and the United States. NOAA Technical Memorandum NMFS-AFSC 264: 1-41.

Strathmann, M.F. 1987. Reproduction and Development of Marine Invertebrates of the Northern Pacific. University of Washington Press, Seattle, Washington, USA.

Thorson, G. 1964. Light as an ecological factor in the dispersal and settlement of larvae of marine bottom invertebrates. Ophelia 1: 167-208. https://doi.org/10.1080/00 785326.1964.10416277

Todd, C.D., and R.W. Doyle. 1981. Reproductive strategies of marine benthic invertebrates: a settlement-timing hypothesis. Marine Ecology Progress Series 4: 5-8. https://doi.org/10.3354/meps004075

Young, C.M., and E. Vazquez. 1995. Morphology, larval development, and distribution of Bathypera feminalba n. sp. (Ascidiacea: Pyuridae), a deep-water ascidian from the fjords and sounds of British Columbia. Invertebrate Biology 114: 89-106. https://doi.org/10.2307/3226958

Received 10 June 2019

Accepted 28 February 2020

\section{SUPPLEMENTARY MATERIALS:}

TABLE S1. All taxa recorded on the settlement plates.

Figure S1. Mean taxa richness observed on a plate by taxonomic level and the side of the settlement plate ( $n=16$ per bar). Figure S2. Mean taxa diversity for solitary organisms observed on a plate by taxonomic level and the side of the settlement plate ( $n=16$ per bar).

Figure S3. Mean taxa diversity for colonial organisms observed on a plate by taxonomic level and the side of the settlement plate $(n=16$ per bar). 